\title{
Heparan sulfate in chronic kidney diseases: exploring the role of 3-O-sulfation
}

Laura Ferreras ${ }^{\text {a }}$, Anna Moles ${ }^{\mathrm{a}, 1}$, Gerhard R Situmorang ${ }^{\mathrm{a}, 2}$, Rana el Masri ${ }^{\mathrm{b}}$, Imogen L Wilson ${ }^{\mathrm{a}}$, Katie Cooke $^{\text {a }}$, Marion Kusche-Gullberg ${ }^{c}$, Romain R Vivès ${ }^{b}$, Neil S Sheerin ${ }^{\text {a,d }}$, Simi Ali a

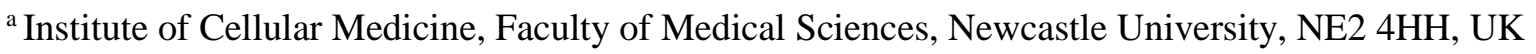

${ }^{\mathrm{b}}$ Univ. Grenoble Alpes, CNRS, CEA, IBS, Grenoble, France

${ }^{c}$ University of Bergen, Department of Biomedicine, Jonas Lies vei 91, N-5009 Bergen, Norway

${ }^{\mathrm{d} N e w c a s t l e}$ upon Tyne Hospitals NHS Foundation Trust and NIHR Newcastle Biomedical Research Centre

Running title: HS 3-O-sulfation in renal fibrosis

Corresponding author:

Professor Simi Ali

Institute of Cellular Medicine

3rd floor William Leech Building

Faculty of Medical Sciences

Newcastle University

$\mathrm{NE} 24 \mathrm{HH}$

UK

simi.ali@ncl.ac.uk

+44(0) 1912087158

\footnotetext{
${ }^{1}$ Anna Moles present address is the Institute of Biomedical Research of Barcelona, Spanish Research Council, Barcelona, Spain.

2. Gerhard R Situmorang present address is the Department of Urology, Faculty of Medicine, Universitas Indonesia, Cipto Mangunkusumo National Referral Hospital, Jakarta, Indonesia.
} 


\begin{abstract}
One of the main feature of chronic kidney disease is the development of renal fibrosis. Heparan Sulfate (HS) is involved in disease development by modifying the function of growth factors and cytokines and creating chemokine gradients. In this context, we aimed to understand the function of HS sulfation in renal fibrosis. Using a mouse model of renal fibrosis, we found that total HS 2-O-sulfation was increased in damaged kidneys, whilst, tubular staining of HS 3-O-sulfation was decreased. The expression of HS modifying enzymes significantly correlated with the development of fibrosis with HS3ST1 demonstrating the strongest correlation. The pro-fibrotic factors TGF $\beta 1$ and TGF $\beta 2 /$ IL $1 \beta$ significantly downregulated HS3ST1 expression in both renal epithelial cells and renal fibroblasts. To determine the implication of HS3ST1 in growth factor binding and signaling, we generated an in vitro model of renal epithelial cells overexpressing HS3ST1 (HKC8-HS3ST1). Heparin Binding EGF like growth factor (HB-EGF) induced rapid, transient STAT3 phosphorylation in control HKC8 cells. In contrast, a prolonged response was demonstrated in HKC8-HS3ST1 cells. Finally, we showed that both HS 3-O-sulfation and HB-EGF tubular staining were decreased with the development of fibrosis. Taken together, these data suggest that HS 3-O-sulfation is modified in fibrosis and highlight HS3ST1 as an attractive biomarker of fibrosis progression with a potential role in HB-EGF signaling.
\end{abstract}




\section{Introduction}

Chronic kidney disease (CKD) is a worldwide health problem affecting $8-16 \%$ of the world's population [1]. CKD is characterised by glomerulosclerosis and interstitial fibrosis and is caused by a wide range of pathologies including metabolic disease, inflammation and vascular damage which finally lead to the accumulation of extracellular matrix [2]. There is currently no treatment that can reverse renal fibrosis, therefore finding new biomarkers and treatments is one of the major challenges in medicine $[2,3]$.

Heparan Sulfate (HS) is a sulfated polysaccharide with a structure consisting of repeating units of uronic acid (UA) linked to a N-acetyl- or N-sulfo-D-glucosamine (GlcNAc, GlcNS), which can vary in length and degree of sulfation. HS is an abundant component of extracellular matrices and cell surfaces, where it is found covalently bound to the core protein of HS proteoglycans (HSPG) [4]. HSPGs regulate the function of growth factors and chemokines by preventing their proteolysis, regulating receptor activation and anchoring them to the extracellular matrix and to the cell surface [5-7]. Due to its role in leukocyte recruitment and in the binding and modulation of pro-fibrotic factors such as TGF $\beta$ [8], HS plays a crucial role in the development of fibrosis $[9,10]$. Furthermore, HS has been associated with renal tissue remodelling as expression of HSPGs including Collagen XVIII and perlecan is increased in interstitial fibrosis of kidney isografts and allografts in rats [11]. In addition, we have previously shown increased HS sulfation on the tubular epithelial cell membranes and in the interstitium of kidneys in patients with chronic rejection [12].

HS can be sulfated at the $\mathrm{N}, 2-\mathrm{O}, 3-\mathrm{O}$ and 6-O position. These modifications are key to its function, as the negative charge provided by the sulfation modulates HS binding to proteins. HS sulfation in the glomerular basement membrane (GBM) has been extensively studied but the role of HS in the glomerular filtration is still not fully understood $[13,14]$. However, it is evident that there is a fundamental change in HS composition in pathological conditions [14,15]. In diabetic patients, disaccharide analysis of the glomerular basement membrane revealed a decrease in 3-O-sulfation [16]. Biopsies from patients with glomerulopathies such as lupus nephritis, membranous glomerulonephritis, minimal change disease and diabetic nephropathy showed a decrease in HS by indirect 
immunofluorescence staining [15]. In contrast, patients with proliferative lupus nephritis had a significant increase of $\mathrm{N}$ - and 2-O-sulfated HS in their glomeruli [17].

Several enzymes are responsible for the biosynthesis and sulfation of HS. The exostosin (EXT) enzymes EXT1 and EXT2 are involved in HS polymerisation [18], while the sulfotransferases add sulfate groups to the carbohydrate backbone. There are four isoforms of $\mathrm{N}$-deacetylase/N-sulfotransferase (NDST), one 2-O-sulfotransferase (HS2ST), seven isoforms of 3-O sulfotransferase (HS3ST) and three isoforms of 6-O sulfotransferase (HS6ST) [19-21]. Additionally, HS can be 6-O-desulfated by two endogenous sulfatases (SULF) [22]. Changes in the expression of enzymes involved in HS biosynthesis are associated with the development of renal dysfunction [23]. Podocyte specific NDST1 knockout led to the development of glomerular hypertrophy together with an increase in mesangial area at 6 months [24]. Additionally, podocyte specific EXT1 knockout mice showed hypertrophic glomeruli and a decrease in highly sulfated HS on the glomerular capillary endothelium [25]. Furthermore, heparanase, an enzyme that cleaves HS from HSPG and releases biologically active oligosaccharide fragments, is also important in the development of renal diseases [26,27]. Heparanase expression is increased in rats with Adriamycin nephropathy [28] and in patients with overt diabetic nephropathy [29]. Heparanase KO mice were protected against the development of diabetic nephropathy [30].

Although HS 3-O sulfation composition and localisation in the kidney have been previously studied [31,32], very little is known about its biological role and possible effects on growth factor function [33]. HS3STs are known to generate the binding motif for antithrombin III and HS herpes simplex virus 1 gD protein, but their activity and substrate specificity are still being studied [34]. These enzymes are not homogeneously expressed in the body and there is increasing evidence that their expression changes during the development of disease. HS3ST2 and HS3ST4 are mainly expressed in the brain $[35,36]$ and there has been interest in HS3ST2 in tauopathies, with its expression increasing in the hippocampus of patients with Alzheimer's disease [37]. HS3ST3 and HS3ST1 are more widely expressed with HS3ST1 mostly expressed in the brain, heart, lung, spleen, stomach, small intestine, colon, testis and the kidney [35,36]. HS3ST1 expression is regulated by a number of factors, with LPS and TNF $\alpha$ reducing its expression in human microvascular endothelial cells [38], whereas expression is increased by IL-4 and 
IL-13 treatment of intestinal epithelial cells [39] and FGF10 treatment of salivary gland epithelia [40]. Reports describing the expression of HS3ST1 during renal transplantation show that it is overexpressed in tolerant patients [41] and in failing grafts [42]. While the first study examined blood samples, the latter analysed tissue expression, which may explain the discrepant findings. These studies did not investigate the mechanism underlying the changes in HS3ST1 expression.

In this study, we have investigated changes in HS sulfation during the development of renal interstitial fibrosis in vivo and determined whether these changes were mirrored by the expression of HS modifying enzymes. Furthermore, we identified factors that modulate the expression of HS3ST1 in renal cells in vitro. Finally, we analysed the implications of the changes in HS3ST1 expression on HB-EGF signalling, a growth factor known to stimulate tubular epithelial cells repair [43], cell motility [44] and is expressed in renal transplants $[45,46]$. 


\section{Materials and Methods}

\subsection{Animal work}

All experiments were carried out under UK Home Office regulations (PPL60/4521) at the Comparative Biology Centre (CBC) in Newcastle University. C57BL/6 mice aged 8-10 weeks were subjected to Unilateral Ureteral Obstruction (UUO). The non-ligated kidney was used as control. Mice kidneys were harvested at 5 and 10 days post-UUO with 6 animals per group. Each kidney collected was dissected for paraffin embedded sections, frozen sections, RNA extraction and HS disaccharide analysis.

\subsection{Cells culture and treatments}

All media were supplemented with $2 \mathrm{mM}$ L-Glutamine, $100 \mathrm{U} / \mathrm{mL}$ Penicillin, $100 \mu \mathrm{g} / \mathrm{mL}$ Streptomycin (Sigma). The immortalised renal tubular epithelial cell line HK2 (ATCC) was grown in Dulbecco's Modified Eagle Medium (DMEM, Sigma, D5671) supplemented with 10\% heat inactivated Fetal Bovine Serum (FBS). The second cell line of immortalised renal epithelial cells studied was HKC8, kindly given by Dr. Racusen [47]. They were cultured in DMEM-F12 (Sigma, D6421) supplemented with 5\% FBS. NKR-49F (ATCC) were cultured in DMEM supplemented with 5\% FBS. All cells were grown in a humidified incubator with $5 \% \mathrm{CO}_{2}$ at $37^{\circ} \mathrm{C}$.

Cell were seeded in complete media until $80 \%$ confluent then in starving medium supplemented with 0.5\% FBS for 16-24 hours. For Western Blot studies, cells were treated with $10 \mathrm{ng} / \mathrm{mL}$ HB-EGF (Sigma E4643). For HS3ST1 expression study, all recombinant human cytokines were purchased from PeproTech and were active in both human and rats. Cells were treated with either $5 \mathrm{ng} / \mathrm{mL}$ TGF $\beta 1(100-$ 21C), $10 \mathrm{ng} / \mathrm{mL}$ TGF $\beta 2(100-35 \mathrm{~B})+10 \mathrm{ng} / \mathrm{mL} \operatorname{IL} 1 \beta(200-01 \mathrm{~B})$.

Human kidney primary proximal tubular epithelial cells (primary PTECs) were isolated from macroscopically normal parts of nephrectomy specimens removed for oncological indications (ethical approval 13/EM/0311). The resected kidney tissue was collected in sterile RPMI 1640 media (SigmaAldrich) supplemented with 5\% FBS and Penicillin (100U/mL) / Streptomycin (100 $\mu \mathrm{g} / \mathrm{ml})$, and was immediately transferred to $4^{\circ} \mathrm{C}$ for subsequent cell isolation procedure. Primary PTECs were isolated using Percoll gradient centrifugation protocol as previously reported [48]. Briefly, samples were 
enzymatically digested with collagenase, mechanically sieved and centrifuged with two discontinuous Percoll gradients (1.04 gram $/ \mathrm{mL}$ and $1.07 \mathrm{gram} / \mathrm{mL})$. This method yielded 1.5 to 2 million cells/gram wet weight of tissue specimen. Primary PTECs were maintained in DMEM/HAM F-12 media (Lonza) supplemented with insulin, hydrocortisone, GA-1000, adrenaline, T3, transferrin, foetal bovine serum, and human epithelial growth factor. Preliminary experiments to characterise the isolated cells showed positive staining of epithelial cell markers, such as ZO-1, E-cadherin, K-cadherin and Cytokeratin. The isolated cells did not express mesenchymal markers, such as $\alpha$-SMA, Vimentin or Collagen type-1. Under light microscope, the cells were hexagonal in shape, and showed "cobblestone-like" appearance with the occasional presence of hemicysts or "dome" formation when grown to form a confluent monolayer. Moreover, scanning electron microscope images of the isolated cells revealed the presence of brush borders, which is a typical feature of kidney tubular epithelial cells. These epithelial characteristics were evident up to the first three passages. Only cells in passage two were used in our experiments.

\subsection{RNAs extraction and quantitative RT-PCR}

In this study, two methods of RNA extraction were used. A column-based method using the Qiagen RNeasy Plus Mini Kit for cells following manufacturer's instructions and a Trizol/Chloroform method for mouse tissue. Briefly, mouse kidney tissue was homogenised in TRI reagent (Ambion) using the Tissue Lyser II by Qiagen. RNA was isolated separated from the protein by adding chloroform (AnalaR) and mixed by inversion. Samples were centrifuged, and the aqueous phase mixed with isopropanol. The RNAs pellet was suspended in $1 \mathrm{~mL}$ of $70 \%$ ethanol, centrifuged and air dried before being suspended in $30 \mu \mathrm{L}$ of RNAse free water (Ambion). To avoid gDNA contamination $1 \mu \mathrm{g}$ of sample was treated with RQ1 DNAse (Promega) for 30 minutes at $37^{\circ} \mathrm{C}$. Next, samples were treated with DNase stop solution (Promega) 10 minutes $65^{\circ} \mathrm{C}$. Complementary DNA (cDNA) was generated using Tetro cDNA synthesis kit (Bioline, BIO-65043) following the manufacturer's instruction. TaqMan probes (Thermofisher) were used to amplify cDNA (see supplementary data, table 1). HPRT was used as housekeeping gene to normalize CT values. For the in vivo work, samples were analysed in six biological replicates done in triplicate and analysed using the comparative $\Delta \Delta \mathrm{CT}$ method. For the in 
vitro work, unless specified, samples were analysed in three biological replicates done in triplicate and analysed using the comparative $\Delta \Delta \mathrm{CT}$ method.

\subsection{HS disaccharide analysis from cells}

Subconfluent $\mathrm{HKC} 8$ cells were cultured with $200 \mu \mathrm{Ci} / \mathrm{ml} \mathrm{Na}_{2}{ }^{35} \mathrm{SO}_{4}$ (Perkin Elmer) for $24 \mathrm{hrs}$ at $37^{\circ} \mathrm{C}$. After incubation, the culture medium was removed and frozen at $-20{ }^{\circ} \mathrm{C}$ for further use. The cell layer was washed twice with cold PBS and solubilized at $4^{\circ} \mathrm{C}$ for $60 \mathrm{~min}$ in $1 \%$ Triton TX-100, $50 \mathrm{mM}$ Tris/ $\mathrm{HCl} \mathrm{pH}$ (7.4), $0,15 \mathrm{M} \mathrm{NaCl}$ and proteinase inhibitors. After centrifugation, the supernatant was collected and an aliquot $(100 \mu \mathrm{l})$ was removed for protein determination using the BCA protein determination kit (Pierce). The remaining supernatant was used for purification of the ${ }^{35} \mathrm{~S}$-labeled polysaccharides. Polysaccharide chains were released from the core protein by treatment with $0.5 \mathrm{M}$ $\mathrm{NaOH}$ over night at $4^{\circ} \mathrm{C}$. After completed ß-elimination, the samples were neutralized with $4 \mathrm{M} \mathrm{HCl}$. Samples were adjusted to $0.15 \mathrm{M} \mathrm{NaCl}$ and applied to a $0.5 \mathrm{ml}$ DEAE-Sephacel column equilibrated in $0.15 \mathrm{M} \mathrm{NaCl}, 0.05 \mathrm{M}$ Tris- $\mathrm{HCl} \mathrm{pH} 7.4,0.1 \%$ Triton $\mathrm{X}-100$. The column was washed with the equilibration buffer, followed by $0.15 \mathrm{M} \mathrm{NaCl}, 0.05 \mathrm{M}$ acetate buffer $\mathrm{pH} 4.0,0.1 \%$ Triton $\mathrm{X}-100$ and $0.05 \mathrm{M}$ Tris/ $\mathrm{HCl} \mathrm{pH}$ 7.5. Finally, the labeled GAG chains were eluted with $1.5 \mathrm{M} \mathrm{NaCl}$ and desalted by gel chromatography using PD-10 columns (Sephadex G-25, Amersham Biosciences) in $\mathrm{H}_{2} \mathrm{O}$. Purified ${ }^{35} \mathrm{~S}$-labeled HS chains were cleaved at $\mathrm{N}$-sulfated GlcN residues by deamination with nitrous acid at $\mathrm{pH} 1.5$ followed by reduction with $\mathrm{NaBH}_{4}$. Labeled deamination products were fractionated by gel chromatography on Sephadex G-15 $(1 \mathrm{~cm}$ x $180 \mathrm{~cm})$ in $0.2 \mathrm{M} \mathrm{NH}_{4} \mathrm{HCO}_{3}$. Fractions corresponding to oligo- and disaccharides were collected and desalted by lyophilization. HS disaccharides analysis was performed with HPLC using a Whatman Partisil 10-SAX column eluted with aqueous $\mathrm{KH}_{2} \mathrm{PO}_{4}$ of stepwise increasing concentration at a rate of $1 \mathrm{ml} / \mathrm{min}$ [49].

\subsection{HS disaccharide analysis from renal samples}

Pooled frozen kidney tissue were collected to generate four groups (D5 Control, D5 UUO, D10 Control, D10 UUO) with each group containing between 35 to $62 \mathrm{mg}$ of frozen tissue. Samples were lysed, digested, purified and analysed as previously described [50]. Briefly, all samples were mechanically 
lysed in $50 \mathrm{mM}$ Tris Buffered Saline, $2 \mathrm{mM}$ EDTA, 6 M Urea and dialysed against $25 \mathrm{mM}$ Tris, $5 \mathrm{mM}$ EDTA $\mathrm{pH}$ 7.8. Following protein degradation in $2 \mathrm{mg} / \mathrm{ml}$ of pronase $24 \mathrm{~h}$ at $37^{\circ} \mathrm{C}$ and two treatments with 5\% v/v trichloroacetic acid, supernatants were washed with $50 \% \mathrm{v} / \mathrm{v}$ diethylether and run onto a DEAE-Sephacel column equilibrated in $20 \mathrm{mM}$ phosphate $\mathrm{pH}$ 6.5. Samples were eluted in $20 \mathrm{mM}$ phosphate, $1 \mathrm{M} \mathrm{NaCl}$ pH 6.5 and desalted using a PD-10 column in $\mathrm{H}_{2} \mathrm{O}$, then lyophilised. GAGs were then resuspended in $100 \mathrm{mM}$ sodium acetate, $0.5 \mathrm{mM} \mathrm{CaCl}_{2}, \mathrm{pH} 7.1$ and digested with $10 \mathrm{mU}$ of heparinase I (Grampian enzymes) overnight at $30^{\circ} \mathrm{C}$, then with $10 \mathrm{mU}$ heparinase II and $10 \mathrm{mU}$ heparinase III (Grampian enzymes) for $24 \mathrm{~h}$ at $37^{\circ} \mathrm{C}$. Following digestion, disaccharides analysis was performed by reverse-phase ion-pair high-performance liquid chromatograph [50] in triplicate.

\subsection{Stable transfectants}

Plasmid EX-TO223-M13 containing flag tagged HS3ST1 enzyme sequence was purchased from GeneCopoeia. Bacterial transformation of E.coli DH5a (Invitrogen) was performed using the heat shock method. Bacterial cells lysis and plasmid purification were performed using Plasmid Mini Kits (Qiagen). To generate an empty plasmid (plasmid without HS3ST1 sequence), $3 \mu \mathrm{g}$ of plasmid were digested with 30U of BsrGI (Bsp 1407I, ThermoFisher). The digested plasmid was extracted using QIAquick Gel Extraction Kit Plasmid extraction. The final plasmid was ligated $3 \mathrm{~h}$ at room temperature using T4 DNA ligase.

Cells transfections were performed using Effectene Reagent (Qiagen) in combination with an enhancer and a DNA-condensation buffer. The following day, fresh media containing $200 \mu \mathrm{g} / \mathrm{mL}$ of selective antibiotic G418 was added to the transfected cells. Colonies were isolated using cloning cylinders.

\subsection{Western Blotting}

Cellular proteins were extracted using CelLytic M (Sigma) complemented with protease (Complete Mini Protease Inhibitor Cocktail, Roche) and phosphatase (Roche) inhibitors. Between 10 to $50 \mu \mathrm{g}$ of protein extract samples were denaturated and electrophoretically separated by Sodium Dodecyl Sulfate (SDS) Polyacrylamide gel electrophoresis, then transferred by semi dry transfer (BioRad) to nitrocellulose membranes (BioRad). Membranes were blocked for $1 \mathrm{~h}$ at room temperature in $0.1 \%$ 
Tween Tris-buffered saline (TBS) with 5\% fat free milk or 5\% Bovine Serum Albumin (BSA) when looking at phosphorylated proteins and probed overnight at $4{ }^{\circ} \mathrm{C}$ using the following primary antibodies diluted in blocking buffer (STAT3 Y705 ab76315 Abcam 1:20 000, alpha tubulin T6074 Sigma 1:4000). Following overnight incubation, membranes were washed in TBS $0.1 \%$ Tween and incubated with the corresponding secondary antibodies conjugated with HorseRadish Peroxidase (R\&D 1:1000), for 1 hour at room temperature. Finally, membranes were washed again, and bands were visualized by enhanced chemiluminescence and exposed to X-ray films.

\subsection{Staining}

Cells were fixed in ice-cold methanol for 5 minutes at $-20^{\circ} \mathrm{C}$, gradually rehydrated with PBS (Sigma, P4417), blocked with 5\% BSA in PBS for 2 hours at room temperature and incubated overnight with primary antibodies (Flag Tag 2368 Cell Signalling 1:3000, GM130 Abcam 1:70). Slides were washed with PBS, then incubated for $2 \mathrm{~h}$ at room temperature with the corresponding secondary antibody (antimouse Alexa fluor 488 ThermoFisher 1:100, anti-rabbit Dylight550, Immunoreagents 1:100). Finally, slides were washed in PBS and mounted with liquid mounting medium containing DAPI (Vectashield).

The use of fluorescently labeled Antithrombin III (AT) for detecting HS 3-O-sufation has been previously described [31]. Fluorescently labeled AT with Alexa fluor 647 was generated following manufacturer's instructions (ThermoFisher Scientific, A20173). Staining specificity was assessed with heparin competition. Cryosections of $7 \mu \mathrm{m}$ thickness were fixed in acetone and blocked with $1 \%$ BSA in PBS for 20 minutes at room temperature. Slides were incubated for 1 hour with labeled antithrombin III and washed three times with blocking buffer. Slides were mounted using Diamond antifade with Dapi.

Mouse kidneys were dissected and fixed in $10 \%$ formalin solution and embedded in paraffin. Serial tissue sections of $4 \mu \mathrm{m}$ thickness were cut and mounted onto slides. Peptide retrieval was performed by microwaving the slides in EDTA buffer. Sections were blocked 10 minutes with 2\% FBS in PBS and incubated overnight at $4^{\circ} \mathrm{C}$ with primary antibody (HB-EGF ab192545 Abcam 1:200, HS4C3 1:5 given by Toin van Kuppevelt, Radboud University, Netherlands). The next day, sections were washed in PBS, 
then incubated with secondary antibody (anti VSV C7706 sigma, Dylight 550 Immunoreagent) diluted in PBS for 1-2 hours at room temperature. Sections were then washed in PBS, incubated with Sudan Black for 20 minutes in the dark at room temperature and finally washed in PBS before mounting with VECTA shield DAPI liquid mounting medium.

Sirius red and Haematoxylin Eosin staining were performed following standard procedures.

All images were analysed using Fiji software. Fluorescent imaging was performed using Leica LCM microscope, Zeiss Axioimager, Nicon A1R confocal microscope. For Sirius red quantification, images were analysed using LeicaQWin analysis software with 10 cortex fields analysed per section for each kidney.

\subsection{Software}

Graphs were created using Microsoft Excel and GraphPad Prism 6.0. Diagrams were generated using Servier Medical Art images (http://servier.com/Powerpoint-image-bank).

\subsection{Statistical Analysis}

Results are expressed as mean \pm Standard Deviation. Statistical evaluations were performed using GraphPad Prism 6.0. Significant results were considered when $\mathrm{P}<0.05\left(^{*}\right), \mathrm{P}<0.01\left(^{* *}\right)$ and $\mathrm{P}<0.001$ (***). P values were calculated using two tailed unpaired student's t-test with Welch's correction. 


\section{Results}

\subsection{Unilateral Ureteral Obstruction induces interstitial fibrosis and modulates HS sulfation}

To assess the structural changes and fibrosis development in the UUO model, kidney sections were stained with H\&E and Sirius red. Sections from day 5 (D5) and 10 (D10) showed tubular dilatation and tubulointerstitial expansion (figure 1A). Additionally, there was a significant increase in interstitial fibrosis as assessed by Sirius red staining when compared with control kidneys at D5 and D10 UUO ( $<<0.05$ and $p<0.001$ respectively) (figure 1B-C). To further address the relevance of the UUO model for HS studies, HS sulfation was evaluated. As shown in figure 1D total HS O-sulfation, measured by reverse-phase ion-pair HPLC, increased in UUO by $13.7 \%$ at D5 and $6.5 \%$ at D10. Assessment of the pattern of HS sulfation showed an increase of total 2-O-sulfation by $45.3 \%$ at D5 and $19.2 \%$ at D10 (figure 1E). HS disaccharide composition (supplementary data, figure 1) revealed an increase of the disulfated disaccharides $\Delta$ UA.2S-GlcNS but a decrease in the monosulfated disaccharides $\Delta U A$ GlcNAc.6S and in the disulfated disaccharides $\Delta$ UA-GlcNS.6S at D5 and D10 UUO. Overall, these results show that UUO-induced renal fibrosis results in changes in HS disaccharide sulfation patterns which could potentially translate in altered protein binding.

\subsection{HS sulfotransferases and sulfatases mRNA expressions are altered in UUO}

In order to investigate whether the increase in HS sulfation was mirrored by a change in the levels of HS sulfotransferases and sulfatases, their expression levels in control and UUO kidneys was analysed by real time qPCR. RNA expression analysis was chosen over protein analysis as endogenous protein levels can be difficult to measure with the antibodies currently available [51]. The increase of HS 2-Osulfation was reflected by a significant increase of HS2ST1 expression at D10 of UUO ( $<<0.01)$ (figure 2A). Additionally, there was a small but significant increase of SULF1 expression at D5 $(\mathrm{p}<0.05)$ (figure 2B) but no detectable expression of HS 6-O-sulfotransferase 1 (HS6ST1) (data not shown). The level of HS3ST3A expression shown in figure 2C decreased at D5 and D10 but only significantly at D5 $(\mathrm{p}<0.05)$. There was a significant increase in expression of HS3ST1 at both D5 and D10 UUO (figure 2D) $(p<0.001)$. Furthermore, HS3ST1 expression correlated significantly with the degree of fibrosis 
assessed by Sirius red staining, Pearson correlation coefficient $r=0.7881$ with $p<0.001$ (figure $2 \mathrm{E}$ ). The other enzymes, HS2ST1, HS3ST3A and SULF1 also showed a correlation with Sirius red staining (supplementary data, figure 2). Taken together, these results suggest that there is an association between the level of fibrosis and the expression of HS modifying enzymes. Because of the highest correlation between HS3ST1 and fibrosis, we then explored the functional implication of this change.
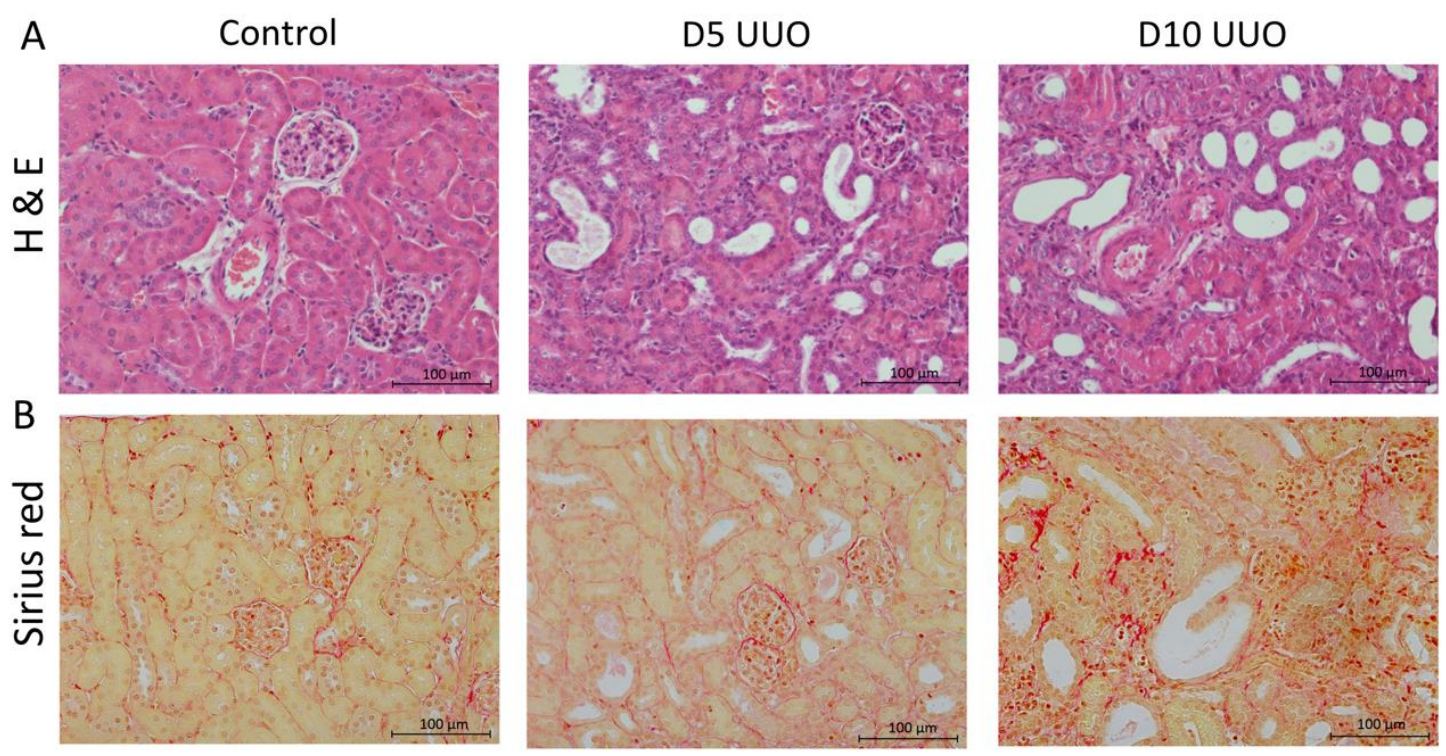

C

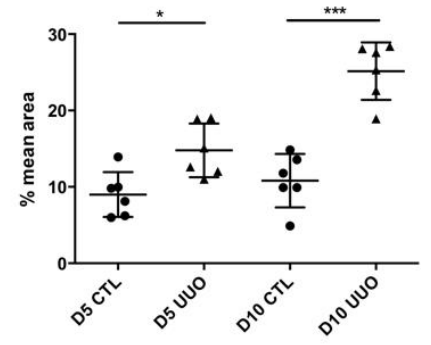

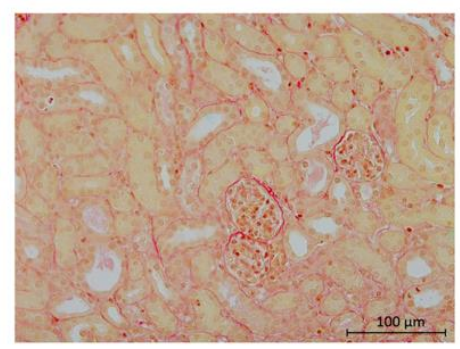

D

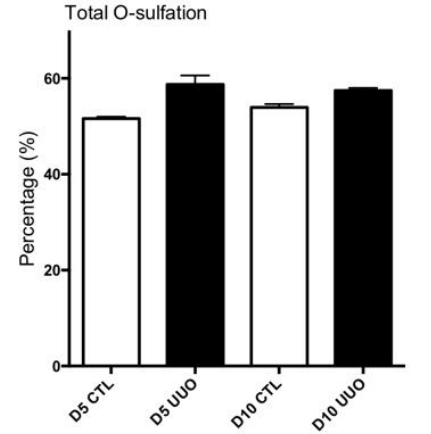

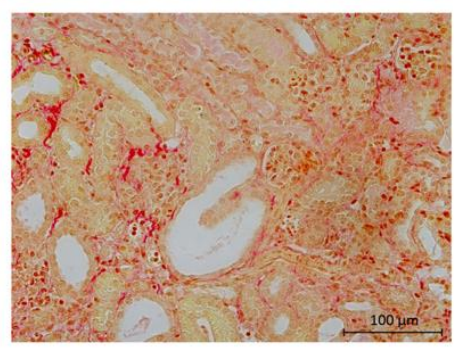

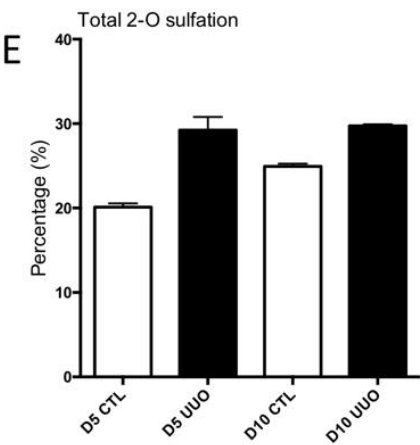

Figure 1. The development of interstitial fibrosis at D5 and D10 of UUO is accompanied by a change in HS sulfation. Representative images of Haematoxylin and Eosin staining (A) and Sirius red staining (B) of cortex from control unobstructed kidney, D5 UUO and D10 UUO. Scale bars represent $100 \mu \mathrm{m}$. Interstitial fibrosis was assessed by Sirius red staining (C). N=6 with 10 cortex fields analysed per section for each kidney, two-tailed unpaired t test, $\mathrm{p}<0.05(*), \mathrm{p}<0.001(* * *)$. HS sulfation of 6 pooled control unobstructed kidney, D5 UUO and D10 UUO is represented as percentage of total disaccharides 
with error bars from technical replicates. Total O-sulfation (D) and total 2-O-sulfation (E). Results are represented as mean $\pm \mathrm{SD}$.

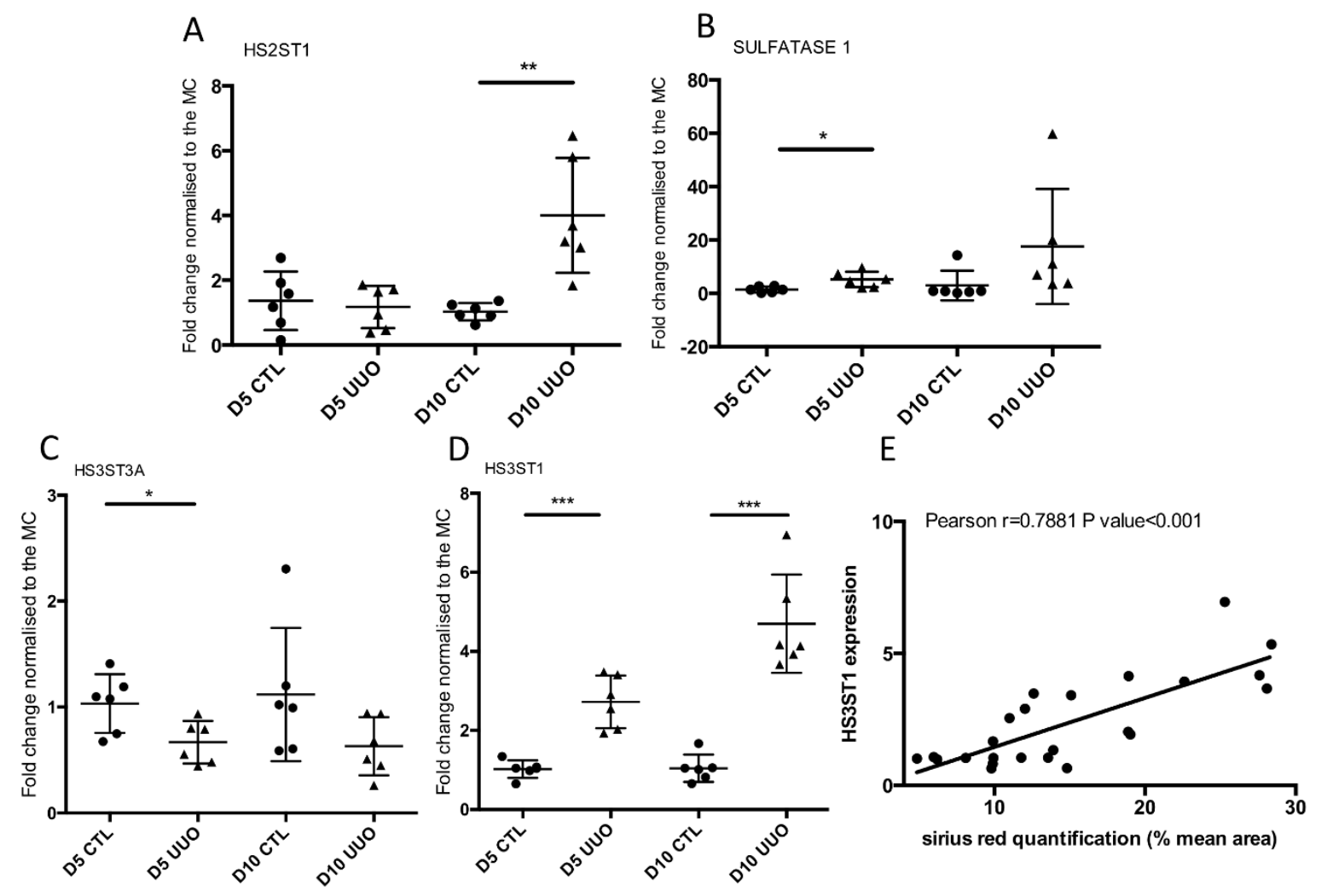

Figure 2. HS sulfotransferases are modulated at D5 and D10 UUO. Expression was adjusted to HPRT1 expression and normalised to the mean of controls (MC) $\mathrm{N}=6$. Two-tailed unpaired $t$ test with Welch's correction with $\mathrm{p}<0.05(*), \mathrm{p}<0.01(* *) \mathrm{p}<0.001\left(^{* * *}\right)$. The Pearson's correlation coefficient was generated with the data from HS3ST1 expression and results from Sirius red staining.

\subsection{Localisation of antithrombin binding HS within control and fibrotic kidneys}

The purpose of analysing antithrombin III binding to the kidney was to localise HS 3-O-sulfation specifically resulting from HS3ST1 and HS3ST5 activity. As HS3ST5 is expressed at very low levels in the kidney [35,52], AT binding can be used as a surrogate marker of HS3ST1 activity. AT binding was seen in the luminal surface of blood vessels, on tubules, around Bowman's capsule and at the vascular pole of the glomerulus (figure 3). In D5 UUO kidney AT binding was not changed in blood vessels and could be observed within the expanded tubulointerstitium (figure 3D). The overall tubular staining decreased. The specificity of AT binding was assessed by competition with soluble heparin, 
which blocked AT binding to tissue sections (supplementary data, figure 3). The reduced tubular binding of AT, and by implication reduced 3-O sulfated HS, is despite the increased expression of HS3ST1 seen in UUO kidneys. The increase of HS3ST1 expression might originate from other cells within the kidney including endothelial that produce AT binding HS [53] or M2 macrophages that express high levels of HS3ST1 [54,55] and are prominent in the UUO model [56]. However, the decrease in HS 3-O-sulfation observed in the tubular compartment was unexpected and further studied.

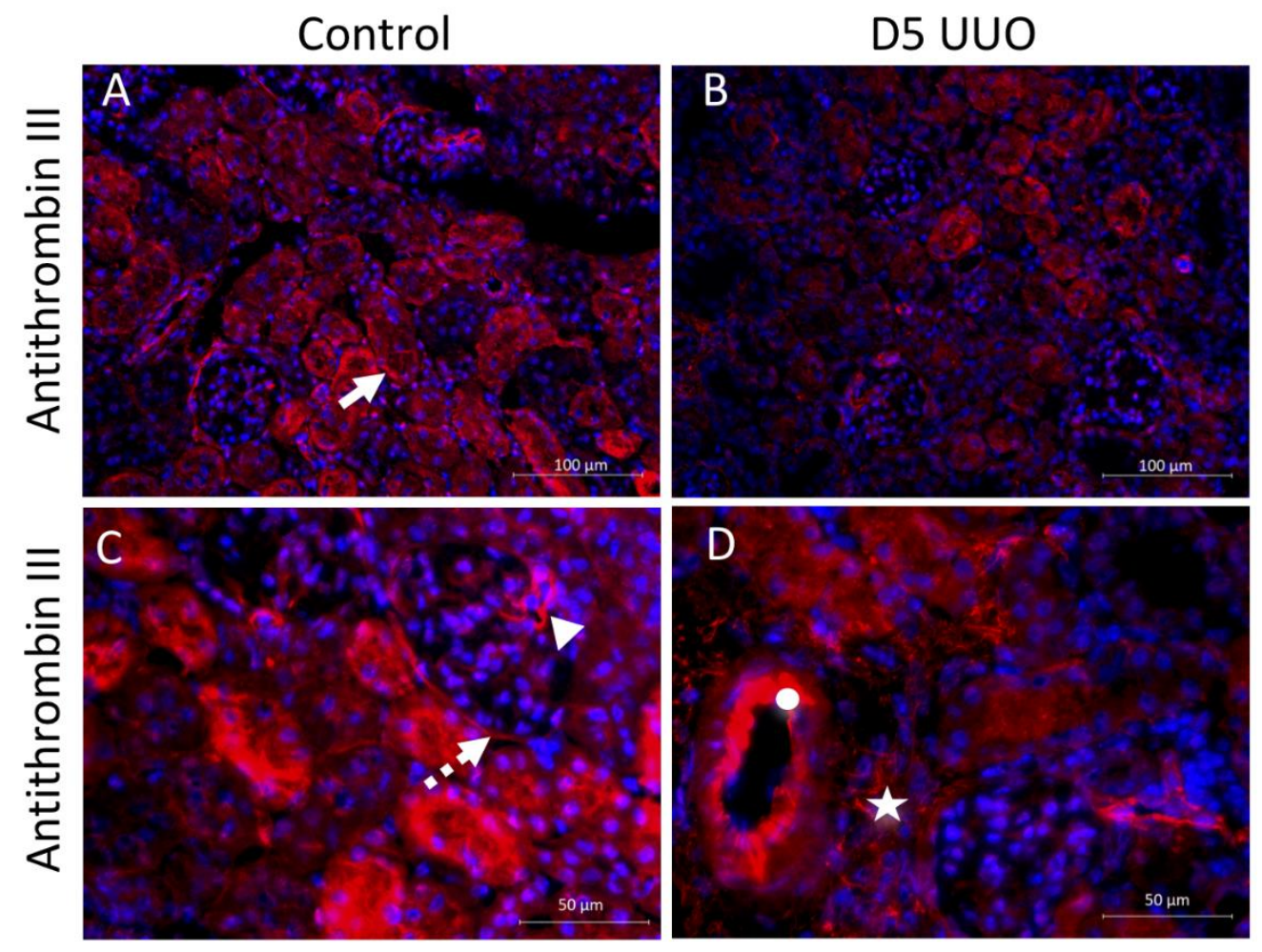

Figure 3. HSPG staining in control and fibrotic renal sections. Representative images of antithrombin III (AT) staining on cryosections from control kidney (A, C) and D5 UUO (B, D). AT was labelled with Alexa fluor 647. AT binding was detectable around Bowman's capsule $(-\rightarrow)$, on blood vessels $(\bigcirc)$, on the tubular basement membrane $(\rightarrow)$, at the vascular pole of the glomerulus $(\Delta)$ and in the expanded interstitium at D5 UUO (放). $\mathrm{N}=6$ with at least 5 cortex fields analysed per section for each kidney. Scale bars represent 100 and $50 \mu \mathrm{m}$. 


\subsection{Modulation of HS3ST1 expression by TGF $\beta 1$, TGF $\beta 2 / \mathrm{IL} 1 \beta$ in renal epithelial cells and renal fibroblasts}

To better understand the role of HS3ST1 in the development of fibrosis, we studied factors influencing HS3ST1 expression in the kidney. Primary human tubular epithelial cells screened for expression of HS3ST-family members by real time qPCR showed that HS3ST1 was the predominant enzyme, followed by HS3ST3A. HS3ST6 and HS3ST3B were expressed at low levels (figure 4A). More replicates may have identified differences in expression of the less abundant enzymes. To understand what modulates HS3ST1 expression in renal tubular epithelial cells, HK2 cells were treated with 5ng/mL TGF $\beta 1$. HS3ST1 expression was downregulated after 6 hours $(\mathrm{p}<0.05)$ and 48 hours $(\mathrm{p}<0.05)$ of treatment. HK2 cells treated with a pro-fibrotic combination of TGF $\beta 2(10 \mathrm{ng} / \mathrm{mL})$ and IL1 $\beta(10$ $\mathrm{ng} / \mathrm{mL})$ [57], also showed significant downregulation of HS3ST1 after 6 hours $(\mathrm{p}<0.05)$ and 24 hours $(\mathrm{p}<0.01)$ of treatment. This downregulation in the expression of HS3ST1 in tubular cells in response to pro-fibrotic stimuli is consistent with the reduced AT binding evident within the tubular compartment during the development of fibrotic disease. The down regulation of HS3ST1 expression was more pronounced in the renal fibroblast cell line NRK-49F (figure 5), with a significant decrease at 6 hours and 24 hours with both TGF $\beta 1$ and combined TGF $\beta 2 / \mathrm{IL} 1 \beta$ ( $\mathrm{p}<0.05$ and $\mathrm{p}<0.01$ respectively). In view of the reduction in tubular H3ST1 expression and the reduction in 3-O sulfation that is likely to result from this change, we next explored the function of 3-O sulfated HS in tubular cells. 

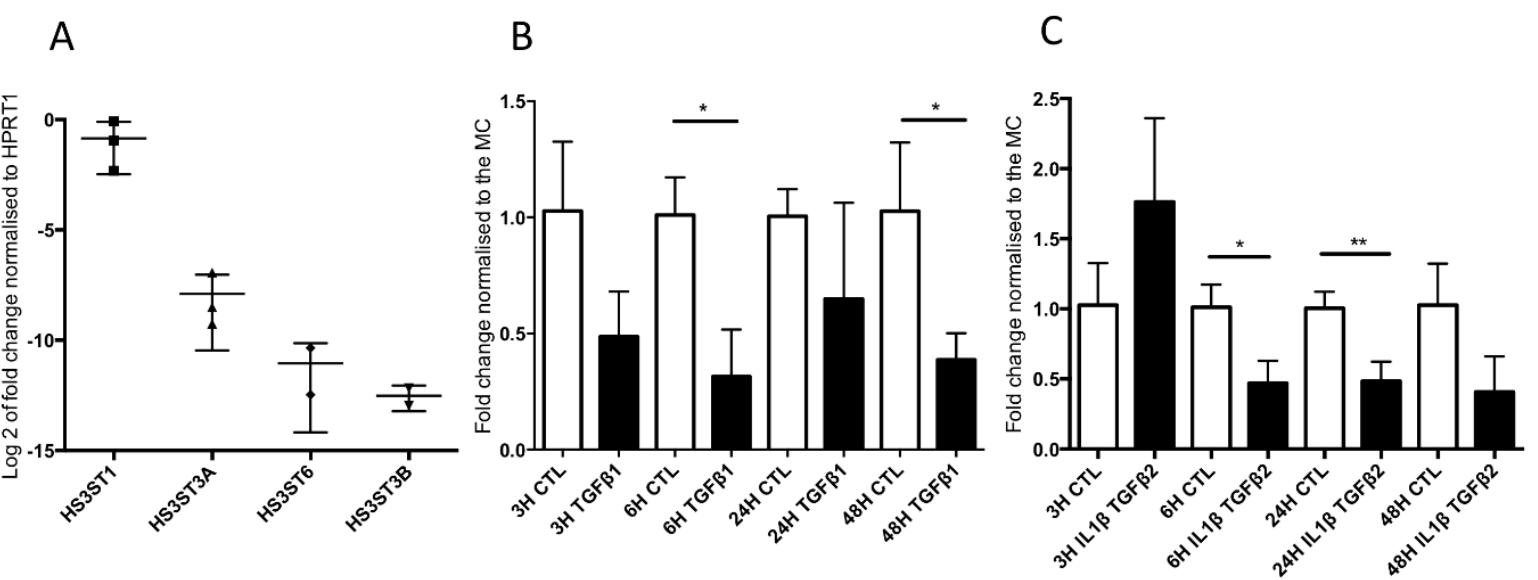

Figure 4. HS3ST1 expression in primary tubular epithelial cells isolated from human kidneys and immortalised renal epithelial cells HK2. Primary tubular epithelial cells were isolated from macroscopically healthy parts of the kidney $\mathrm{N} \geq 2$. Results are displayed as $\log 2$ of HS3ST1 fold change normalised to HPRT1 (A). HK2 cells were incubated 24h in 0.5\% FBS and treated for 3, 624 and 48 hours with $5 \mathrm{ng} / \mathrm{mL}$ TGF $\beta 1$ (B) and $10 \mathrm{ng} / \mathrm{mL}$ TGF $\beta 2$ IL1 $\beta$ (C) or maintained in media alone (CTL). Results are expressed by mean $\pm \mathrm{SD} \mathrm{N}=3$ and were normalised to the mean of controls (MC). Twotailed unpaired $\mathrm{t}$ test with Welch's correction with $\mathrm{p}<0.05(*), \mathrm{p}<0.01(* *)$.

A

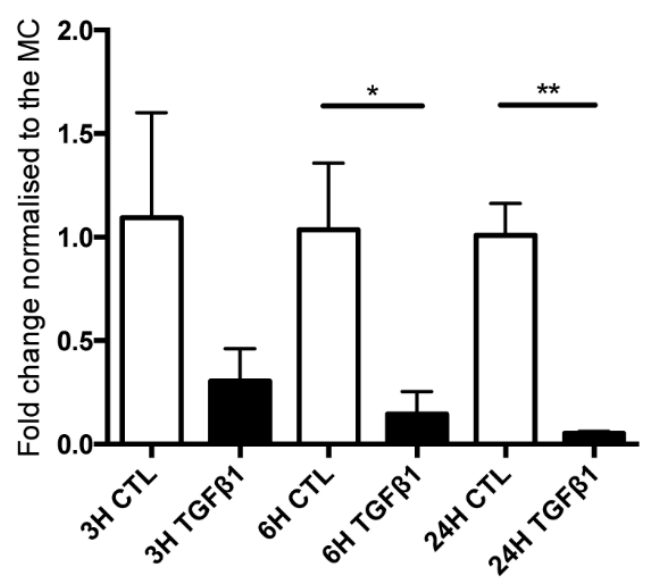

$\mathrm{B}$

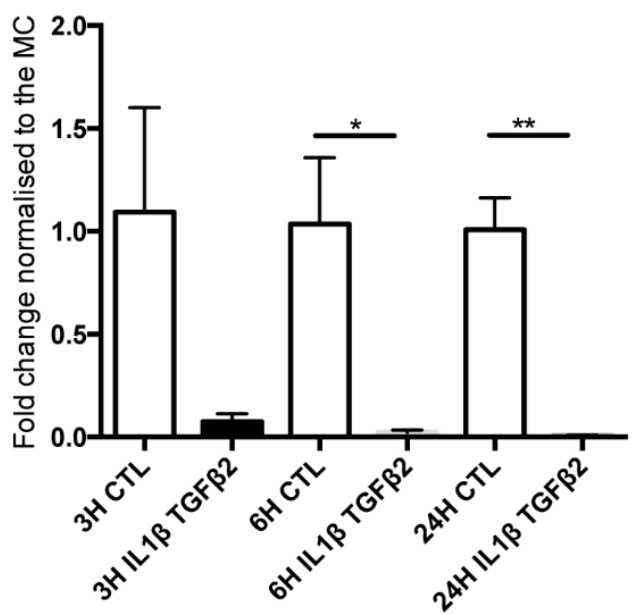

Figure 5. HS3ST1 expression is decreased in immortalised rat fibroblast NRK-49F cells following profibrotic treatments. Cells were incubated 24 hours in $0.5 \%$ FBS and treated for 3, 6 and 24 hours with $5 \mathrm{ng} / \mathrm{mL}$ TGF $\beta 1$ (A) and $10 \mathrm{ng} / \mathrm{mL}$ TGF $\beta 2$ IL1 $\beta$ (B) or maintained in media alone (CTL). Results 
are expressed by mean $\pm \mathrm{SD} \mathrm{N}=3$ and were normalised to the mean of controls (MC). Two-tailed unpaired $\mathrm{t}$ test with Welch's correction with $\mathrm{p}<0.05(*), \mathrm{p}<0.01(* *)$.

\subsection{Identification of HB-EGF as a potential growth factor modulated by HS 3-O-sulfation}

The renal epithelial cell line HKC8 was stably transfected with either an empty plasmid (HKC8-CTL) or with a plasmid containing the HS3ST1 sequence (HKC8-HS3ST1). HKC8-CTL and HKC8-HS3ST1 were screened for protein expression and localisation by immunofluorescence (figure 6A). HS3ST1flag co-localised with the cis Golgi and around the nucleus. To address the functionality of the HS3ST1 present in the HKC8-HS3ST1 cells, HS disaccharide analysis was performed after metabolic labeling of HKC8-CTL and HKC8-HS3ST1 (figure 6B). There was no detectable HS 3-O-sulfation in the HKC8-CTL but after transfection with HS3ST1, approximately $3.7 \%$ (figure 6B) and $1.6 \%$ (supplementary data, figure 4) of total 35S labelled disaccharides eluted as 3-O-sulfated disaccharides in two different clones of HKC8-HS3ST1. The exact nature of the disaccharides needs to be further identified. However, its elution position and resistance to beta-glucuronidase (data not shown) indicates that this peak (eluting at approximately 80 minutes) represents IdoA-GlcNS3S6S in the intact polysaccharide. HB-EGF is known to bind to HSPG and can signal through STAT3. The signalling pattern was studied by assessing the phosphorylation of STAT3 (Y705). HB-EGF induced phosphorylation of STAT3 after 5 minutes of stimulation, which then diminished by 1 hour in HKC8CTL. However, HKC8-HS3ST1 showed a strong signal at 5 minutes, with continued phosphorylation at 1 hour in two clones (figure 6C). Taken together, these data show that the overexpression of HS3ST1 can affect HB-EGF signalling. The relevance of this finding in vivo was further studied using the UUO model. 
A

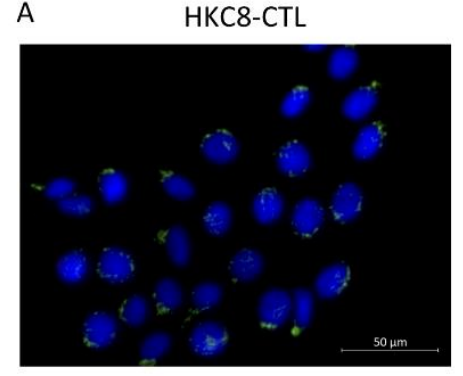

$$
\text { c }
$$

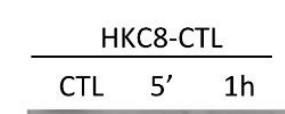

P STAT3

Tubulin

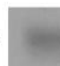

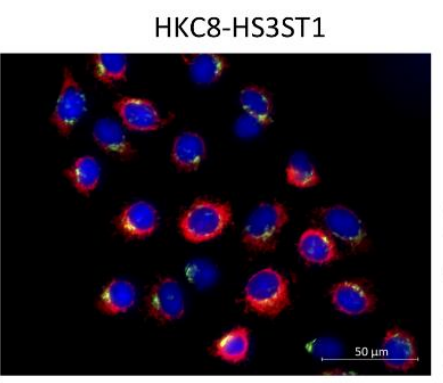

HKC8-HS3ST1

$\begin{array}{llllll}\text { CTL } & 5^{\prime} & \text { 1h } & \text { CTL } & 5^{\prime} & 1 \mathrm{~h}\end{array}$

B

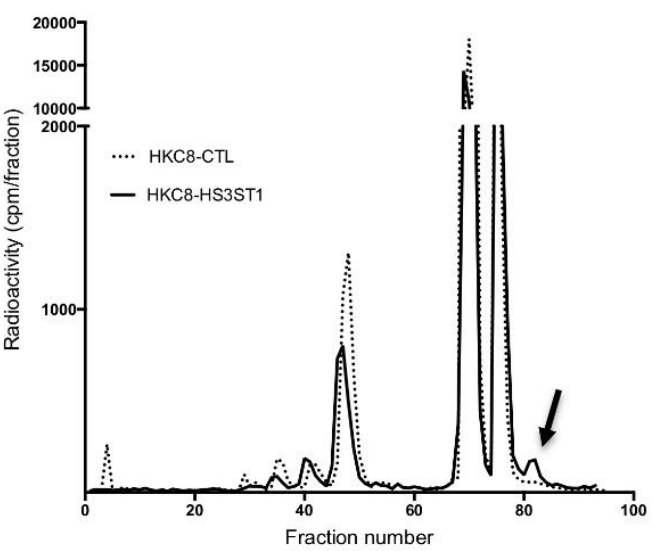

Figure 6. HS3ST1 overexpressing cells have more HS 3-O-sulfation and a different HB-EGF signalling. In stably transfected HKC8 cells, HS3ST1 expression was assessed by immunofluorescence (A) HS3ST1-FLAG is shown in red and GM130, a cis Golgi membrane marker, in green. Scale bar represents $50 \mu \mathrm{m}$. HS disaccharide analysis (B) showed no 3-O-sulfation in the mock (HKC8-CTL) and a small amount in the transfected cells HKC8-HS3ST1 $(\rightarrow)$. HB-EGF signalling via P-STAT3 was analysed at 5 minutes and 1 hour in mock transfected cells HKC8-CTL and in two different clones of HS3ST1 transfected cells, HKC8-HS3ST1, N=3 (C).

\subsection{Total HS 3-O-sulfation and HB-EGF staining in renal fibrosis}

HB-EGF staining was predominantly found on the basement membranes of tubules. The staining was not uniform, with some cortical tubules, most likely proximal tubules, staining more strongly than others (figure 7). A similar staining was observed at D5 and D10 UUO, but with a noticeable decrease in intensity (figure 7). Total HS 3-O-sulfation was analysed using the phage display antibody HS4C3, which recognises highly sulfated HS when 3-O-sulfation is present. The staining was similar to the AT staining but with a more intense staining in the glomerulus. Furthermore, and in agreement with the results from the AT staining (figure 3), the staining for HS 3-O-sulfation decreased during the development of fibrosis. In conclusion, both HB-EGF and HS 3-O-sulfation are present on the tubular basement membrane and both are decreased during the development of fibrosis. However, both staining did not seem to colocalise. 

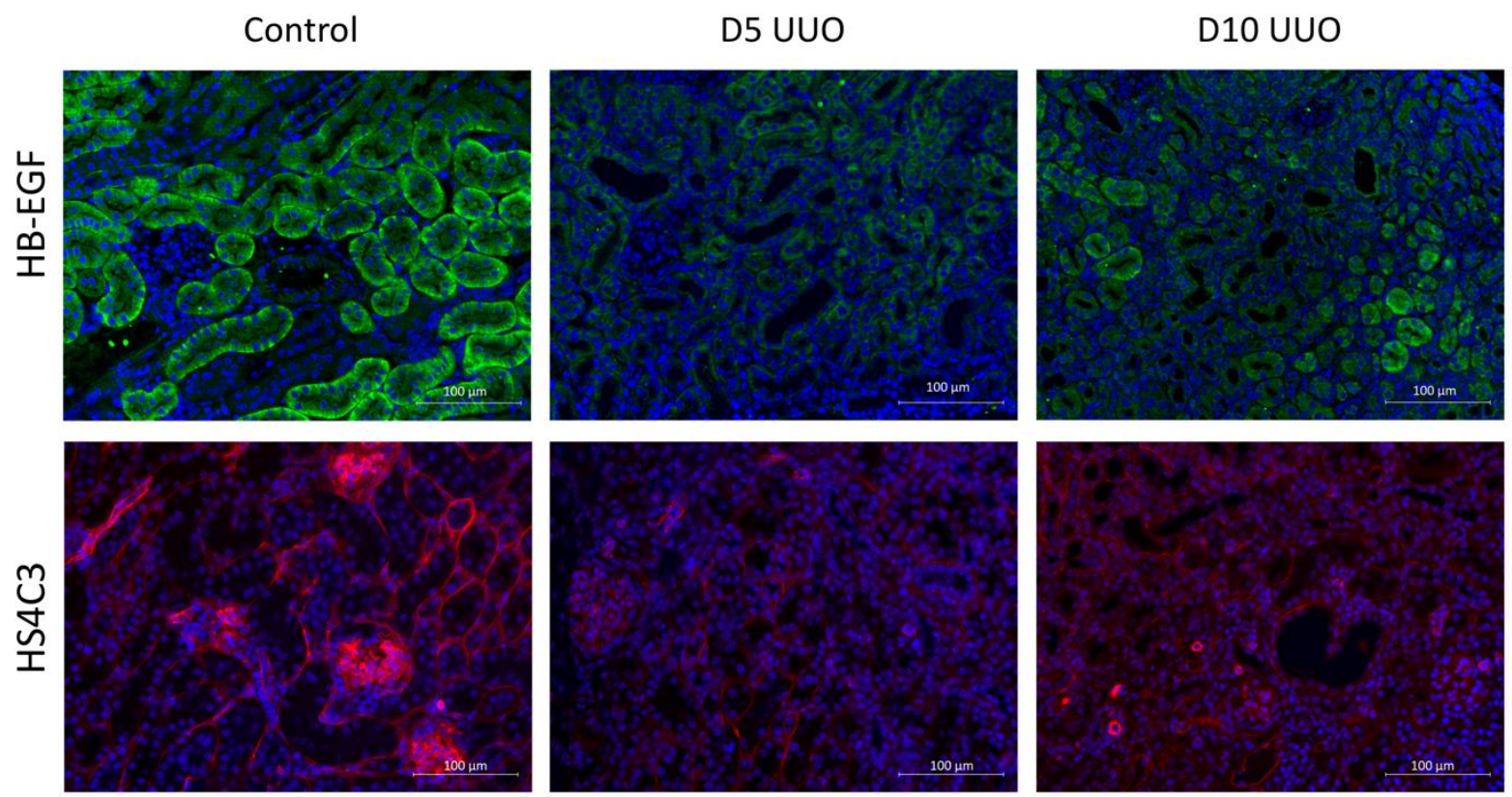

Figure 7. Staining of HB-EGF and total HS 3-O-sulfation. Representative images of HB-EGF and HS4C3 staining on paraffin embedded sections of control tissues, D5 UUO and D10 UUO. HB-EGF staining was mainly present on the tubular basement membrane. The HS4C3 antibody, which stains heavily sulfated HS, showed glomerular, vascular and tubular staining. N=6 with 10 cortex fields analysed per section for each kidney. Scale bars represent $100 \mu \mathrm{m}$. 


\section{Discussion}

We hypothesise that, changes in HS O-sulfation in diseased kidneys alters growth factor binding and activity, potentially promoting either repair or fibrosis. We have shown here that there are changes in the pattern of HS sulfation during the development of renal fibrosis. Total HS O-sulfation was increased mainly due to an increase in 2-O-sulfation. Our results are consistent with the increase of HS 2-Osulfation observed in tissue from patients with idiopathic pulmonary fibrosis [58] in which its role during tissue remodelling was proposed. 2-O-sulfation is known to be important for binding multiple growth factors for example members of the FGF family $[59,60]$. Due to the lack of HS 3-O-sulfation standards for the tissue disaccharides analysis, we could not analyse 3-O-sulfation during the evolution of UUO. Altered HS expression may be an attempt to increase growth factor activity and promote repair. However, in the context of persistent or repeated injury, the outcome may be fibrosis and loss of function.

The increase in HS 2-O-sulfation was mirrored by an increase in HS2ST1 expression. Surprisingly, HS6ST1 expression was too low to be analysed but the HS sulfatase SULF1, that removes 6-O-sulfate groups, was also increased in UUO tissue. The increase in SULF1 expression can be explained by the presence of TGF $\beta 1$ in fibrotic tissue, a growth factor known to induce SULF1 expression [61]. Furthermore, HS3ST3A expression was decreased in renal fibrosis while HS3ST1 expression was increased and showed a strong correlation with the amount of fibrosis. SULF1 and HS3ST1 expression were previously found to be increased in fibrotic liver and in patients with hepatocellular carcinoma [62]. Taken together, these data highlight the potential of HS enzymes as markers of disease development.

Recently, there has been an increased interest in the function of HS 3-O-sulfation. In mouse embryos, HS 3-O-sulfation supported stem cell differentiation [63]. In the brain, HS3STs were found to regulate axonal growth cone collapse in mice [64] and neuronal development in Caenorhabditis elegans [65]. Furthermore, HS3STs have been extensively studied in cancer [66-68]. The impact of the increase of HS3ST1 expression was analysed with staining for 3-O-sulfation. There was an overall decrease in HS 3-O-sulfation in UUO tissue, particularly in the tubular compartment. There are several potential 
explanations for this decrease. First, the decrease in 3-O-sulfation might be explained by the presence of highly 2-O sulfated disaccharides that prevent HS3ST1 action and therefore by a low level of suitable HS precursor disaccharides as has been described in glomerular epithelial cells [31]. The increase of HS3ST1 mRNA might be an unsuccessful attempt to increase the level of HS 3-O-sulfation. Second, HS 3-O-sulfation was only analysed by immunofluorescence and potentially the 3-O-sulfation was masked by growth factors bound to it. Lastly, an increase in HS3ST1 expression may occur in endothelial or infiltrating immune cells such as macrophages, masking a reduction in tubular cell HS3ST1 expression. HS3ST1 expression could be increased in some cells but decreased in others.

This study also aimed to identify regulators of HS3ST1 expression. TGF $\beta 1$ is known to be a pro-fibrotic factor [69] and TGF $\beta 2 / \mathrm{IL} 1 \beta$ are implicated in endothelial to mesenchymal transition, a mechanism that contributes to fibrosis [57]. Both treatments downregulated HS3ST1 expression in renal fibroblasts and renal epithelial cells. Other enzymes such as SULF1 and SULF2 have been shown to be modulated by TGF $\beta 1$ [61] and heparanase is implicated in the regulation of TGF $\beta 1$ expression in tubular cells [70]. Taken together, these data show a relationship between TGF $\beta$ signalling and the expression of HS modifying enzymes. HS sulfation is known to influence protein binding and it is not surprising that pro fibrotic factors would be implicated in its regulation. Although we have looked at epithelial cells and fibroblasts, expression in tissues will be influenced by other cell types as well. Indeed, previous studies have shown that HS3ST enzyme expression by endothelial cells [38] and immune cells [71] is controlled by pro-inflammatory factors.

In order to study the effect of HS3ST1 expression on growth factor binding, we developed an in vitro model of renal epithelial cells overexpressing HS3ST1. Overexpression of HS3ST1 had an effect on HS disaccharide composition including a small but reproducible increase in HS 3-O-sulfation (up to $3.7 \%$ ) (figure 6 and supplementary data figure 4). This level of sulfation might seem low, but HS 3-O sulfation is a rare modification. In previous work on anticoagulant HS chains, 3-O sulfated glucosamine residues represented around $1 \%$ in porcine endothelial cells [53] and 6\% in follicular fluid [72]. In CHO cells overexpressing HS3ST1, HS containing AT binding site represented 4\% of the total HS [73]. 
Very little is known about the effect of 3-O-sulfated HS on growth factor function. HB-EGF can bind EGF receptor and induce STAT phosphorylation [74]. This happens rapidly and in control cells the response diminishes by 1 hour. In contrast, in cells overexpressing HS3ST1 the STAT phosphorylation is evident at 1 hour, suggesting that the cellular response to HB-EGF is altered by the presence of $\mathrm{HS}$ 3-O-sulfation. The mechanism of this delayed response remains to be elucidated, but a previous paper suggested that a delayed response to HB-EGF could be mediated by a second messenger such as IL-6 [75]. HB-EGF plays a role in cellular repair [43] and was found to be protective in the development of liver fibrosis [76,77]. A decrease in tubular 3-O-sulfated HS staining was seen together with a decrease in HB-EGF during UUO. This could affect the capacity for tubular repair and worsen the severity of injury. It is also possible that in addition to reduced 3-O-sulfation, other structural changes in HS such as the increase in 2-O-sulfation are affecting HB-EGF binding. Further studies are required to elucidate precisely which HS structures can modify HB-EGF binding.

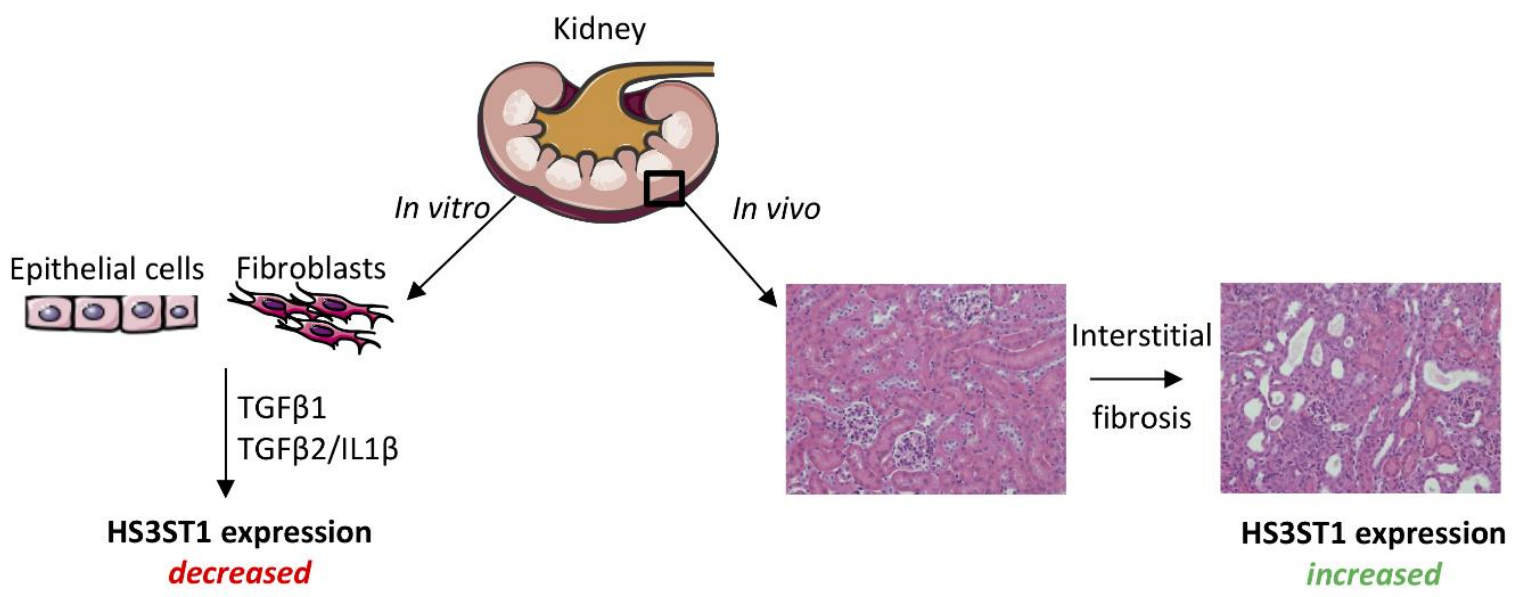

Figure 8 . The complex regulation of HS3ST1 in fibrosis. HS3ST1 expression is strongly modulated in fibrosis. While in vivo data showed a strong correlation between HS3ST1 expression and the development of fibrosis, in vitro data showed a decreased expression following TGF $\beta 1$ and TGF $\beta 2 /$ IL1 $\beta$ treatment. Graphical illustrations were produced using Servier Medical Art (www.servier.com).

In conclusion, we believe this study has highlighted the complexity of the regulation of HS 3-Osulfation and its potential role in renal fibrosis (figure 8). The strong correlation between the increase 
of HS3ST1 expression and the development of fibrosis, the changes in sulfation patterns during disease and the functional consequences of these changes all highlight the importance of studying HS 3-Osulfation. A better understanding of HS biology may lead to more effective strategies to measure or modify sulfation for diagnostic or therapeutic benefit. 


\section{Acknowledgements}

This work was funded by the European Commission FP7 in the framework of the Prolong Organ Survival After Transplantation, Initial Training Networks, 606979, by the Northern Counties Kidney Research Fund and by the French National Agency for Research (ANR-12-BSV8-0023). The Research was also supported by NIHR Newcastle Biomedical Research Centre. The authors would like to thank Dr Jeremy Palmer, Newcastle University, for the AT labeling help and the Bioimaging facility, Newcastle University for their support in imaging. The authors are grateful to Mona Gronning,

University of Bergen for HS compositional analyses of cells and Toin van Kuppevelt, Radboud University Medical Center for providing the HS4C3 antibody.

Declarations of interest: none. 


\section{References}

1 Jha V, Garcia-Garcia G, Iseki K, et al. Chronic kidney disease: Global dimension and perspectives. Lancet 2013;382:260-272.

2 Breyer MD, Susztak K. The next generation of therapeutics for chronic kidney disease. Nat Rev Drug Discov 2016;15:568-588.

3 Genovese F, Manresa AA, Leeming DJ, et al. The extracellular matrix in the kidney: a source of novel non-invasive biomarkers of kidney fibrosis? Fibrogenesis Tissue Repair 2014;7:4.

4 Bishop JR, Schuksz M, Esko JD. Heparan sulphate proteoglycans fine-tune mammalian physiology. Nature 2007;446:1030-1037.

$5 \quad$ Ferreras L, Sheerin NS, Kirby JA, et al. Mechanisms of Renal Graft Chronic Injury and Progression to Interstitial Fibrosis. Curr Transplant Reports 2015;2:259-268.

6 Iozzo R V, Schaefer L. Proteoglycan form and function: A comprehensive nomenclature of proteoglycans. Matrix Biol 2015;42:11-55.

7 Iozzo R V. Heparan sulfate proteoglycans: intricate molecules with intriguing functions. J Clin Invest 2001;108:165-167.

8 Lyon M, Rushton G, Gallagher JT. The Interaction of the Transforming Growth Factor- $\mathrm{s}$ with Heparin/Heparan Sulfate Is Isoform-specific. J Biol Chem 1997;272:18000-18006.

9 Ali S, Hardy L a, Kirby J a. Transplant immunobiology: a crucial role for heparan sulfate glycosaminoglycans? Transplantation 2003;75:1773-1782.

10 Massena S, Christoffersson G, Hjertström E, et al. A chemotactic gradient sequestered on endothelial heparan sulfate induces directional intraluminal crawling of neutrophils. Blood 2010;116:1924-1931.

11 Rienstra H, Katta K, Celie JW a M, et al. Differential expression of proteoglycans in tissue remodeling and lymphangiogenesis after experimental renal transplantation in rats. PLoS One 2010;5:e9095.

12 Alhasan AA, Spielhofer J, Kusche-Gullberg M, et al. Role of 6-O-sulfated heparan sulfate in chronic renal fibrosis. J Biol Chem 2014;289:20295-20306.

13 Goldberg S, Harvey SJ, Cunningham J, et al. Glomerular filtration is normal in the absence of both agrin and perlecan-heparan sulfate from the glomerular basement membrane. Nephrol Dial Transplant 2009;24:2044-2051.

14 Borza DB. Glomerular basement membrane heparan sulfate in health and disease: A regulator of local complement activation. Matrix Biol 2017;57-58:299-310.

15 Van Den Born J, Van Den Heuvel LPWJ, Bakker MA, et al. Distribution of GBM heparan sulfate proteoglycan core protein and side chains in human glomerular diseases. Kidney Int 1993;43:454-463.

16 Edge AS, Spiro RG. A specific structural alteration in the heparan sulphate of human glomerular basement membrane in diabetes. Diabetologia 2000;43:1056-1059.

17 Rops AL, van den Hoven MJ, Bakker MA, et al. Expression of glomerular heparan sulphate domains in murine and human lupus nephritis. Nephrol Dial Transplant 2007;22:1891-1902.

18 Busse M, Feta A, Presto J, et al. Contribution of EXT1, EXT2, and EXTL3 to heparan sulfate chain elongation. J Biol Chem 2007;282:32802-32810.

19 Rabenstein DL. Heparin and heparan sulfate: structure and function. Nat Prod Rep 
2002;19:312-331.

20 El Masri R, Seffouh A, Lortat-Jacob H, et al. The "in and out" of glucosamine 6-O-sulfation: the 6th sense of heparan sulfate. Glycoconj J 2017;34:285-298.

21 Li JP, Kusche-Gullberg M. Heparan Sulfate: Biosynthesis, Structure, and Function. Int Rev Cell Mol Biol 2016;325:215-273.

22 Vivès RR, Seffouh A, Lortat-Jacob H. Post-Synthetic Regulation of HS Structure: The Yin and Yang of the Sulfs in Cancer. Front Oncol 2014;3:331.

23 Talsma DT, Katta K, Ettema MAB, et al. Endothelial heparan sulfate deficiency reduces inflammation and fibrosis in murine diabetic nephropathy. Lab Invest 2018;98:427-438.

24 Sugar T, Wassenhove-Mccarthy DJ, Esko JD, et al. Podocyte-specific deletion of NDST1, a key enzyme in the sulfation of heparan sulfate glycosaminoglycans, leads to abnormalities in podocyte organization in vivo. Kidney Int 2014;85:307-318.

25 Chen S, Wassenhove-McCarthy DJ, Yamaguchi Y, et al. Loss of heparan sulfate glycosaminoglycan assembly in podocytes does not lead to proteinuria. Kidney Int 2008;74:289-299.

26 Van Den Hoven MJ, Rops AL, Vlodavsky I, et al. Heparanase in glomerular diseases. Kidney Int 2007;72:543-548.

27 Masola V, Zaza G, Onisto M, et al. Impact of heparanase on renal fibrosis. J Transl Med 2015;13:181.

28 Kramer A. Induction of Glomerular Heparanase Expression in Rats with Adriamycin Nephropathy Is Regulated by Reactive Oxygen Species and the Renin-Angiotensin System. J Am Soc Nephrol 2006;17:2513-2520.

29 Van Den Hoven MJ, Rops AL, Bakker MA, et al. Increased expression of heparanase in overt diabetic nephropathy. Kidney Int 2006;70:2100-2108.

30 Gil N, Goldberg R, Neuman T, et al. Heparanase is essential for the development of diabetic nephropathy in mice. Diabetes 2012;61:208-216.

31 Girardin EP, HajMohammadi S, Birmele B, et al. Synthesis of anticoagulantly active heparan sulfate proteoglycans by glomerular epithelial cells involves multiple 3-O-sulfotransferase isoforms and a limiting precursor pool. J Biol Chem 2005;280:38059-38070.

32 Edge ASB, Spiro RG. Characterization of novel sequences containing 3-O-sulfated glucosamine in glomerular basement membrane heparan sulfate and localization of sulfated disaccharides to a peripheral domain. J Biol Chem 1990;265:15874-15881.

33 Thacker BE, Xu D, Lawrence R, et al. Heparan sulfate 3-O-sulfation: a rare modification in search of a function. Matrix Biol 2014;35:60-72.

34 Wang Z, Hsieh PH, Xu Y, et al. Synthesis of 3-O-Sulfated Oligosaccharides to Understand the Relationship between Structures and Functions of Heparan Sulfate. J Am Chem Soc 2017;139:5249-5256.

35 Mochizuki H, Yoshida K, Shibata Y, et al. Tetrasulfated disaccharide unit in heparan sulfate: Enzymatic formation and tissue distribution. J Biol Chem 2008;283:31237-31245.

36 Shworak NW, Liu J, Petros LM, et al. Multiple isoforms of heparan sulfate D-glucosaminyl 3$\mathrm{O}$-sulfotransferase. Isolation, characterization, and expression of human cdnas and identification of distinct genomic loci. J Biol Chem 1999;274:5170-5184. 
abnormal phosphorylation of tau in Alzheimer's disease-related tau pathology. Brain 2015;138:1339-1354.

38 Krenn EC, Wille I, Gesslbauer B, et al. Glycanogenomics: a qPCR-approach to investigate biological glycan function. Biochem Biophys Res Commun 2008;375:297-302.

39 Takeda K, Hashimoto K, Uchikawa R, et al. Direct effects of IL-4/IL-13 and the nematode Nippostrongylus brasiliensis on intestinal epithelial cells in vitro. Parasite Immunol 2010;32:420-429.

40 Patel VN, Lombaert IMA, Cowherd SN, et al. Hs3st3-Modified Heparan Sulfate Controls KIT+ Progenitor Expansion by Regulating 3-O-Sulfotransferases. Dev Cell 2014;29:662-673.

41 Sagoo P, Perucha E, Sawitzki B, et al. Development of a cross-platform biomarker signature to detect renal transplant tolerance in humans. J Clin Invest 2010;120:1848-1861.

42 Einecke G, Reeve J, Sis B, et al. A molecular classifier for predicting future graft loss in late kidney transplant biopsies. J Clin Invest 2010;120:1862-1872.

43 Sakai M, Zhang MZ, Homma T, et al. Production of heparin binding epidermal growth factorlike growth factor in the early phase of regeneration after acute renal injury: Isolation and localization of bioactive molecules. J Clin Invest 1997;99:2128-2138.

44 Takemura T, Hino S, Okada M, et al. Role of membrane-bound heparin-binding epidermal growth factor-like growth factor (HB-EGF) in renal epithelial cell branching. Kidney Int 2002;61:1968-1979.

45 Celie JWAM, Katta KK, Adepu S, et al. Tubular epithelial syndecan-1 maintains renal function in murine ischemia/reperfusion and human transplantation. Kidney Int 2012;81:651661.

46 Talsma DT, Daha MR, Van Den Born J. The bittersweet taste of tubulo-interstitial glycans. Nephrol Dial Transplant 2017;32:611-619.

47 Racusen LC, Monteil C, Sgrignoli A, et al. Cell lines with extended in vitro growth potential from human renal proximal tubule: Characterization, response to inducers, and comparison with established cell lines. J Lab Clin Med 1997;129:318-329.

48 Brown CDA, Sayer R, Windass AS, et al. Characterisation of human tubular cell monolayers as a model of proximal tubular xenobiotic handling. Toxicol Appl Pharmacol 2008;233:428 438.

49 Smeds E, Habuchi H, Do A-T, et al. Substrate specificities of mouse heparan sulphate glucosaminyl 6-O-sulphotransferases. Biochem J 2003;372:371-380.

50 Hijmans RS, Shrestha P, Sarpong KA, et al. High sodium diet converts renal proteoglycans into pro-inflammatory mediators in rats. PLoS One 2017;12:e0178940.

51 Sembajwe LF, Katta K, Grønning M, et al. The exostosin family of glycosyltransferases: mRNA expression profiles and heparan sulphate structure in human breast carcinoma cell lines. Biosci Rep 2018;38.

52 Mochizuki H, Yoshida K, Gotoh M, et al. Characterization of a heparan sulfate 3-Osulfotransferase-5, an enzyme synthesizing a tetrasulfated disaccharide. J Biol Chem 2003;278:26780-26787.

53 Marcum JA, Atha DH, Fritze LMS, et al. Cloned bovine aortic endothelial cells synthesize anticoagulantly active heparan sulfate proteoglycan. J Biol Chem 1986;261:7507-7517.

54 Martinez P, Denys A, Delos M, et al. Macrophage polarization alters the expression and sulfation pattern of glycosaminoglycans. Glycobiology 2015;25:502-513. 

macrophage differentiation and polarization: new molecules and patterns of gene expression. J Immunol 2006;177:7303-7311.

56 Pan B, Liu G, Jiang Z, et al. Regulation of renal fibrosis by macrophage polarization. Cell Physiol Biochem 2015;35:1062-1069.

57 Maleszewska M, Moonen J-RAJ, Huijkman N, et al. IL-1 $\beta$ and TGF $\beta 2$ synergistically induce endothelial to mesenchymal transition in an NFkB-dependent manner. Immunobiology 2013;218:443-454.

58 Westergren-Thorsson G, Hedström U, Nybom A, et al. Increased deposition of glycosaminoglycans and altered structure of heparan sulfate in idiopathic pulmonary fibrosis. Int J Biochem Cell Biol 2017;83:27-38.

59 Ashikari-Hada S, Habuchi H, Kariya Y, et al. Characterization of Growth Factor-binding Structures in Heparin/Heparan Sulfate Using an Octasaccharide Library. J Biol Chem 2004;279:12346-12354.

60 Turnbull JE, Fernig DG, Ke Y, et al. Identification of the basic fibroblast growth factor binding sequence in fibroblast heparan sulfate. J Biol Chem 1992;267:10337-10341.

61 Yue X, Li X, Nguyen HT, et al. Transforming growth factor-beta1 induces heparan sulfate 6O-endosulfatase 1 expression in vitro and in vivo. J Biol Chem 2008;283:20397-20407.

62 Tátrai P, Egedi K, Somorácz Á, et al. Quantitative and qualitative alterations of heparan sulfate in fibrogenic liver diseases and hepatocellular cancer. J Histochem Cytochem 2010;58:429441.

63 Hirano K, Sasaki N, Ichimiya T, et al. 3-O-sulfated heparan sulfate recognized by the antibody HS4C 3 contribute to the differentiation of mouse embryonic stem cells via fas signaling. PLoS One 2012;7:e43440.

64 Thacker BE, Seamen E, Lawrence R, et al. Expanding the 3-O-Sulfate Proteome - Enhanced Binding of Neuropilin-1 to 3-O-Sulfated Heparan Sulfate Modulates Its Activity. ACS Chem Biol 2016;11:971-980.

65 Tecle E, Diaz-Balzac CA, Bülow HE. Distinct 3-O-sulfated heparan sulfate modification patterns are required for kal-1-dependent neurite branching in a context-dependent manner in Caenorhabditis elegans. G3 (Bethesda) 2013;3:541-552.

66 Kumar AV, Gassar ES, Spillmann D, et al. HS3ST2 modulates breast cancer cell invasiveness via MAP kinase-and Tcf4 (Tcf712)-dependent regulation of protease and cadherin expression. Int J Cancer 2014;135:2579-2592.

67 Hellec C, Delos M, Carpentier M, et al. The heparan sulfate 3-O-sulfotransferases (HS3ST) 2, 3B and 4 enhance proliferation and survival in breast cancer MDA-MB-231 cells. PLoS One 2018;13:e0194676.

68 Mao X, Gauche C, Coughtrie MWH, et al. The heparan sulfate sulfotransferase 3-OST3A (HS3ST3A) is a novel tumor regulator and a prognostic marker in breast cancer. Oncogene 2016;35:5043-5055.

69 Leask A, Abraham DJ. TGF-beta signaling and the fibrotic response. FASEB J 2004;18:816827.

70 Masola V, Zaza G, Secchi MF, et al. Heparanase is a key player in renal fibrosis by regulating TGF- $\beta$ expression and activity. Biochim Biophys Acta 2014;1843:2122-2128.

71 Sikora AS, Delos M, Martinez P, et al. Regulation of the Expression of Heparan Sulfate 3-OSulfotransferase 3B (HS3ST3B) by Inflammatory Stimuli in Human Monocytes. J Cell 
Biochem 2016;117:1529-1542.

72 De Agostini AI, Dong JC, Arrighi CDV, et al. Human follicular fluid heparan sulfate contains abundant 3-O-sulfated chains with anticoagulant activity. J Biol Chem 2008;283:2811528124.

73 Datta P, Li G, Yang B, et al. Bioengineered chinese hamster ovary cells with golgi-targeted 3O-sulfotransferase-1 biosynthesize heparan sulfate with an antithrombin-binding site. J Biol Chem 2013;288:37308-37318.

74 Knudsen SLJ, Wai Mac AS, Henriksen L, et al. EGFR signaling patterns are regulated by its different ligands. Growth Factors 2014;32:155-163.

75 Lee KS, Park JH, Lee S, et al. HB-EGF induces delayed STAT3 activation via NF-אB mediated IL-6 secretion in vascular smooth muscle cell. Biochim Biophys Acta - Mol Cell Res 2007;1773:1637-1644.

76 Takemura T, Yoshida Y, Kiso S, et al. Conditional knockout of heparin-binding epidermal growth factor-like growth factor in the liver accelerates carbon tetrachloride-induced liver injury in mice. Hepatol Res 2013;43:384-393.

77 Huang G, Besner GE, Brigstock DR. Heparin-binding epidermal growth factor-like growth factor suppresses experimental liver fibrosis in mice. Lab Investig 2012;92:703-712.

\section{Supplementary data}
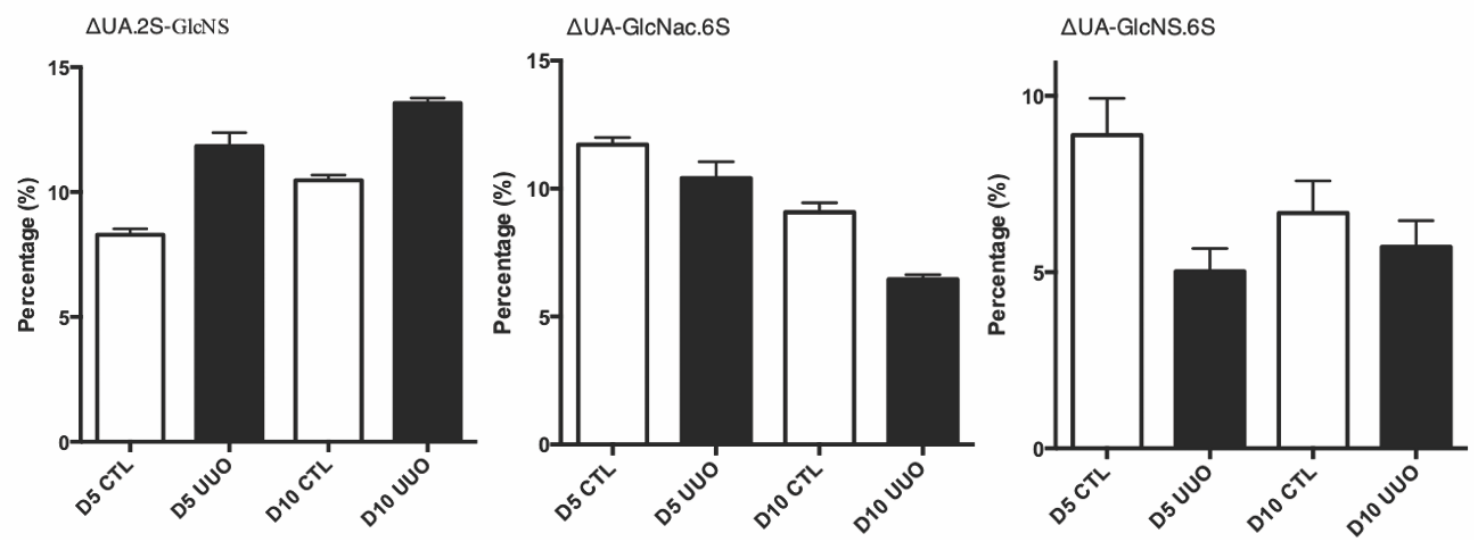

Supplementary figure 1. HS sulfation of 6 pooled control unobstructed kidney, D5 UUO and D10

UUO is represented as percentage of total disaccharides with error bars from technical replicates. 

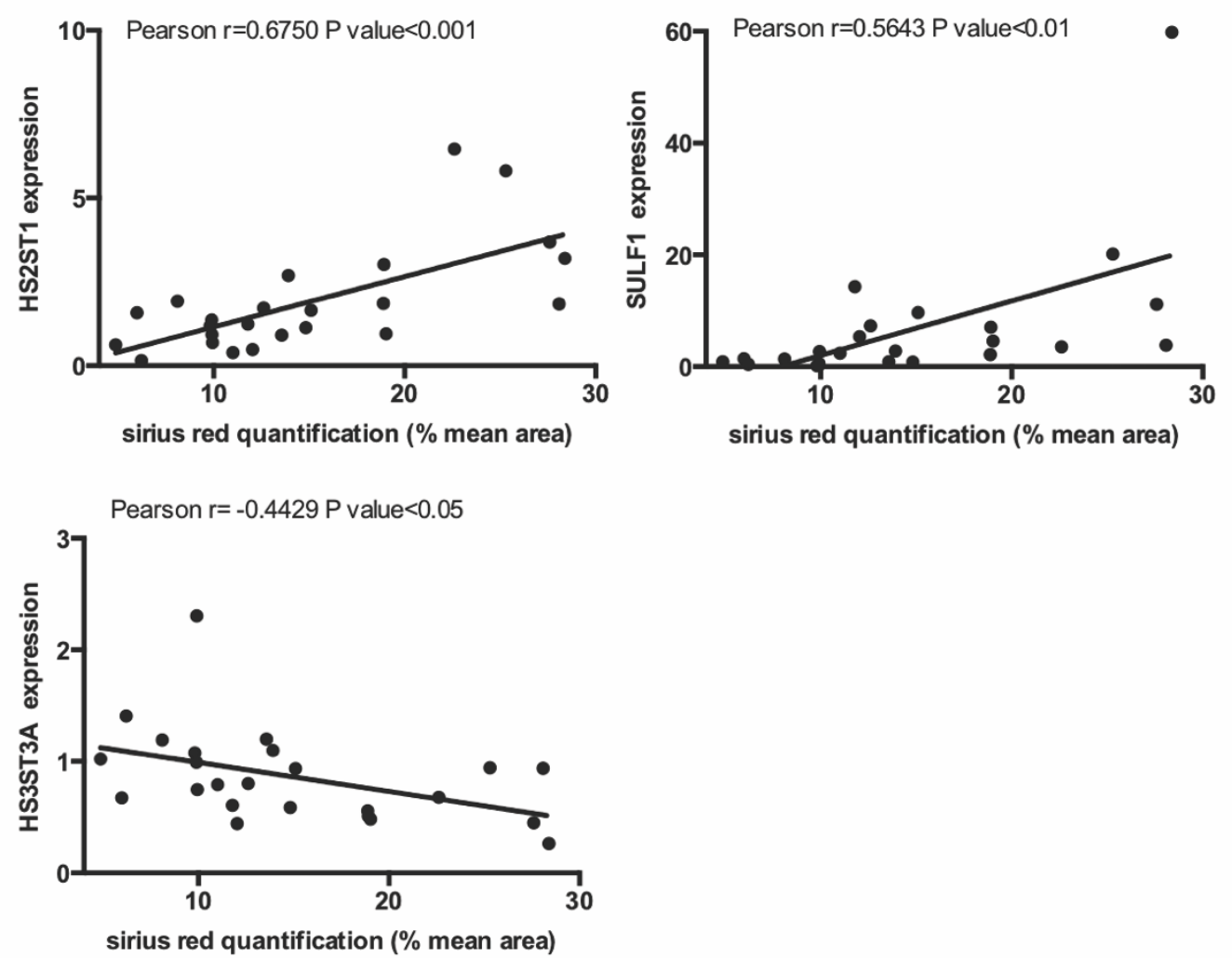

Supplementary figure 2. HS modifying enzymes correlation to Sirius red staining.

\section{ATIII}

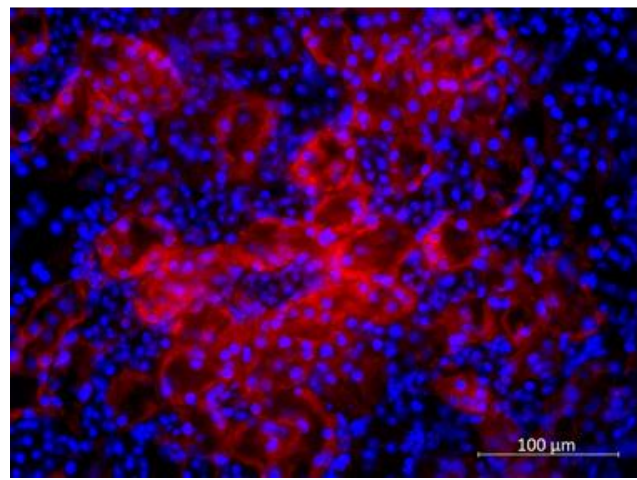

AT III + Heparin (20 $\mu \mathrm{M})$

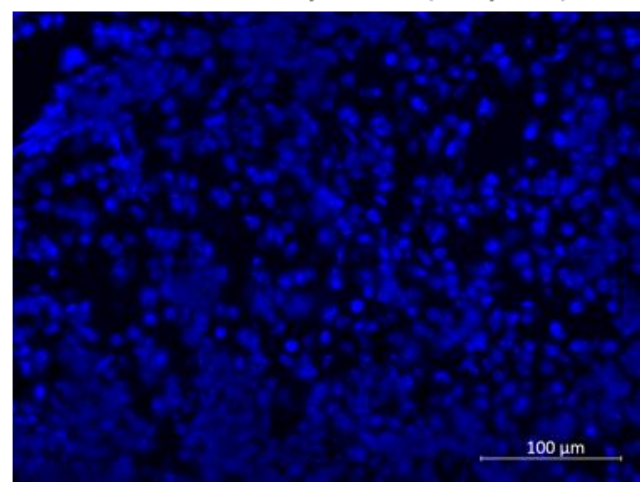

Supplementary figure 3. Antithrombin III staining specificity was assessed on mouse kidney tissue by incubating 1 hour with labelled ATIII or with ATIII and $20 \mu \mathrm{M}$ heparin. The ATIII staining was abolished by incubating with $20 \mu \mathrm{M}$ of heparin. Scale bars represent $100 \mu \mathrm{m}$. 


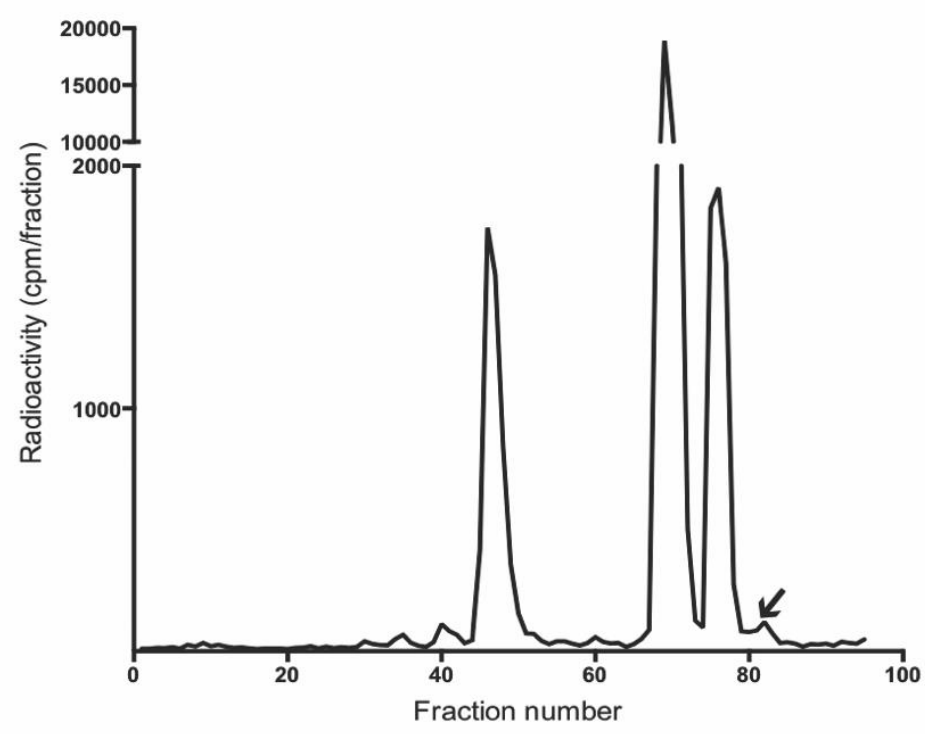

Supplementary figure 4. HS disaccharide analysis of a different overexpressing cellular clone than shown in figure 6B showed 1.6\% HS 3-O-sulfation $(\rightarrow)$

\begin{tabular}{|l|l|r|r|}
\hline \multicolumn{1}{|c|}{ Species } & \multicolumn{1}{|c|}{ Gene name } & Gene Symbol & \multicolumn{1}{c|}{ Reference } \\
\hline Human & Heparan sulfate-glucosamine 3-O-sulfotransferase 3B1 & HS3ST3B1 & Hs01391447_m1 \\
\hline Human & Heparan sulfate-glucosamine 3-O-sulfotransferase 1 & HS3ST1 & Hs00245421_s1 \\
\hline Human & Heparan sulfate-glucosamine 3-O-sulfotransferase 3A1 & HS3ST3A & Hs00925624_s1 \\
Human & Hypoxanthine guanine phosphoribosyl transferase & HPRT1 & Hs02800695_m1 \\
\hline Human & Heparan sulfate-glucosamine 3-O-sulfotransferase 1 & HS3ST1 (for plasmid) & Hs01099196_m1 \\
Human & Heparan sulfate-glucosamine 3-O-sulfotransferase 6 & HS3ST6 & Hs03007244_m1 \\
\hline Mouse & Heparan sulfate (glucosamine) 3-O-sulfotransferase 1 & HS3ST1 & Mm01964038_s1 \\
Mouse & Heparan sulfate (glucosamine) 3-O-sulfotransferase 3A & HS3ST3A1 & Mm000780907_s1 \\
Mouse & Hypoxanthine guanine phosphoribosyl transferase & HPRT & Mm03024075_m1 \\
Mouse & Sulfatase 1 & SULF1 & Mm00552283_m1 \\
Mouse & Heparan Sulfate 2-O-sulfotransferase 1 & HS2ST1 & Mm00478684_m1 \\
\hline
\end{tabular}

Supplementary table 1 . Gene expression was determined using TaqMan probes from ThermoFisher. Hs: Homo sapiens, Mm: Mus musculus. Suffix m indicates probes that are designed between two exons whereas $\mathrm{s}$ defines probes that bind within a single exon. 